\title{
EDUCAÇÃO SUPERIOR, INTERNACIONALIZAÇÃO E CIRCULAÇÃO DE IDEIAS: AJUSTANDO OS TERMOS E DESFAZENDO MITOS*
}

\author{
Mário Luiz Neves de Azevedo \\ da Universidade Estadual de Maringá (UEM); \\ Afrânio Mendes Catani \\ da Universidade de São Paulo (USP).
}

\begin{abstract}
Resumo: O artigo tem por objetivo analisar o fenômeno da internacionalização da educação superior, o compartilhamento da cultura e a circulação internacional de ideias. Dessa forma, o texto foi desenvolvido tendo por referência a "teoria dos campos sociais" de Pierre Bourdieu, para investigar a atual manifestação da internacionalização da educação superior, que pode adquirir os sentidos da solidariedade ou da mercadorização. $\mathrm{O}$ artigo também versa a respeito do Programa "Ciência sem Fronteiras" e da “Estratégia Nacional de Ciência, Tecnologia e Inovação 2012 2015" do Brasil.

Palavras-Chave: Internacionalização. Educação superior. Ciência sem Fronteiras.
\end{abstract}

INTRODUÇÃO

Eu gostaria de oferecer-lhes hoje algumas reflexões que escapam ao ritual de celebração da amizade franco-alemã e de obrigatórias considerações sobre identidade e alteridade. Penso que, em matéria de amizade, como em todos os assuntos, a lucidez não é absolutamente antitética à afeição, muito pelo contrário. Então, eu gostaria de tentar oferecer algumas reflexões sobre as condições sociais da circulação internacional de ideias, ou, empregando um vocabulário da área econômica, que produz sempre um efeito de ruptura, sobre o que poderia ser chamado de importação-exportação intelectual. (BOURDIEU, 2002, p. 1) ${ }^{1}$

\footnotetext{
* Artigo recebido em 14/10/2012 e aprovado em 05/12/2012.
} 
Pierre Bourdieu inicia sua conferência de 30 de outubro de 1989, na ocasião da inauguração do Centro Francês da Universidade de Freiburg (Frankreich-Zentrum), com as palavras citadas na epígrafe. O sociólogo francês entende que, mesmo nas ocasiões de celebração, como era o caso naquele momento, e de enaltecimento da amizade franco-alemã, não poderia colocar de lado a lucidez, pois, afinal, essa não se opõe (ou contradiz) ao sentimento de fraternidade entre os povos. Portanto, para compreender o fenômeno da circulação internacional de ideias e da internacionalização da educação superior, é requerido o tratamento científico-histórico de um lado, não descartando, por outro, que essa aproximação investigativa também carrega sentimentos, sejam os de afinidade ou mesmo de contrariedade.

Isso porque a circulação de ideias e a educação, inclusive a superior, necessariamente, implicam em compartilhamento de cultura e de conhecimento. Isso pode ocorrer tanto em nível restrito, para as elites, quanto de maneira ampla, sem discriminação de classes; tanto em plano nacional, com vista à unificação, como internacional, para a promoção da solidariedade entre os povos. Assim, conceber "cultura como civilidade" e "cultura como solidariedade", de acordo com Eagleton (2000, p. 112), pode significar somente a reunião de "inimigos jurados"; porém, também pode, de forma inversa, transformar essas junções (cultura/civilidade e cultura/ solidariedade) em potentes "aliados".

Dessa forma, o presente artigo procura analisar o fenômeno da internacionalização da educação superior, o compartilhamento da cultura e a circulação internacional de ideias que - conforme poderá ser verificado à luz da categoria de contradição - pode adquirir o sentido humanista da solidariedade e da civilidade, ou o sentido coisificante da expansão capitalista e da mercadorização (commodification).

\section{CAMPO ACADÊMICO, A PRODUÇÃO DO CONHECIMENTO E A INTERNACIONALIZAÇÃO}

Acredita-se frequentemente que a vida intelectual é espontaneamente internacional. Nada é mais falso. (BOURDIEU, 2002, p. 3)²

O campo acadêmico internacional ou global, esquematicamente, comporta os espaços sociais ocupados pelos atores sociais, portadores de passaportes simbólicos que lhes permitem o reconhecimento científico pelos pares e a circulação transfronteiriça de suas ideias, seja pelo deslocamento pessoal, por intermédio da exposição de seu capital cultural incorporado (cursos, conferências e palestras), ou pela distribuição de seu capital objetivado em livros, revistas, jornais e demais publicações. A 
internacionalização acadêmica permite, ainda, a integração e a regionalização da educação superior e da produção científica. ${ }^{3}$

Destarte, como em qualquer outra área social, o campo científico ou o acadêmico, de acordo com Bourdieu (2004, p 22-23), "é um campo de forças e um campo de lutas para conservar ou transformar este campo de forças", de modo que a sua estrutura é a estrutura da distribuição do capital científico entre os diferentes atores sociais.

O campo científico tem sua autonomia minorada, como é sabido, ao submeter-se à indução dos Estados e aos editais das agências de financiamento nacionais, a exemplo, com relação ao campo científico no Brasil, do Ministério da Ciência e Tecnologia (MCT), Ministério da Educação (MEC), CNPq, Capes, ${ }^{4}$ Finep e outras fundações de apoio à pesquisa, vinculadas aos estados subnacionais, assim como às agências internacionais, como a Fundação Ford, Fulbright, DAAD, Campus-France, Comissão Europeia etc.. Essa asserção pode tornar-se um pouco mais clara, recuperando-se o que observou Bourdieu, ao ensaiar uma "sociologia clínica do campo científico":

O campo científico é um mundo social e, como tal, faz imposições, solicitações etc., que são, no entanto, relativamente independentes das pressões do mundo social global que o envolve [...]. Dizemos que quanto mais autônomo for um campo, maior o seu poder de refração [...]. O grau de autonomia de um campo tem por indicador principal seu poder de refração, de retradução. Inversamente, a heteronomia de um campo se manifesta, essencialmente, pelo fato de que os problemas exteriores, em especial os problemas políticos, aí se exprimem de maneira direta. (BOURDIEU, 2004, P. 21-22)

Nesse sentido, o campo científico, como todo campo social - mais ou menos autônomo -, possui objeto(s) em disputa e regras de funcionamento tácitas e consentidas pelos atores sociais. Segundo Azevedo,

A internacionalização acadêmica é um fenômeno intrínseco ao movimento dos atores sociais em luta pela conquista do reconhecimento em seu campo científico correspondente em que, mesmo que suas ações sejam espontâneas, desprendidas ou aleatórias são catalisadas por políticas públicas indutoras de produção científica. (AZEVEDO, 2009, p. 186)

Marília Morosini - tomando por pressuposto a ideia segundo a qual a chamada "Sociedade do conhecimento identifica como marco da educação superior a acentuada expansão das instituições com influência marcante da globalização" (MOROSINI, 2011, p. 94) - afirma que "a produção do conhecimento científico-tecnológico baseado na pesquisa está concentrada na pós-graduação" (p. 98). A autora tece uma série de considerações 
para dizer, em suma, que a globalização é um conceito complexo, com grande diversidade de termos relacionados - como mundialização, internacionalização da educação superior, cooperação internacional-, e que, de maneira similar a outros fatos sociais, sofre interferência de tempo e de espaço (p. 94). A autora ainda observa:

Assim, podemos citar: a dimensão internacional, presente no século XX, caracterizando-se por ser uma fase incidental mais do que organizada; a educação internacional, atividade organizada preferentemente por razões políticas e de segurança nacional; e a internacionalização da educação superior, posterior à guerra fria, processo estratégico ligado à globalização e à regionalização das sociedades e seu impacto na educação superior. (MOROSINI, 2011, p. 94)

Em seu artigo, Morosini analisa também o processo de internacionalização da educação superior, modelos e estratégias, destacando que há dois modelos de cooperação científica. Primeiramente, referenciando-se em Jorge Brovetto, ${ }^{5}$ anuncia o modelo de Cooperação Internacional Tradicional (CIT), sendo que tal cooperação é caracterizada por relações de competitividade entre as IES na captação de "sujeitos e de consumidores". A ênfase é posta nos contatos internacionais e nas atividades que fortalecem as IES, principalmente as de pesquisa e de pós-graduação, havendo grande mobilidade de estudantes e de pesquisadores (MOROSINI, 2011, p. 95).

O segundo modelo mencionado por Morosini intitula-se Cooperação Internacional Horizontal $(\mathrm{ClH})$, desenvolvido originalmente por Axel Didriksson. ${ }^{6}$ Tal modelo se desenvolveria "com base na solidariedade e na consciência internacional e se oporia ao modelo tradicional de cooperação internacional, no qual o mercado tem o domínio dos princípios" (2011, p. 96). Didriksson escreve que "os atores locais são os principais responsáveis pelo desenho e formulação das propostas, programas e projetos de mudança e os atores principais do processo de transformação" (apud MOROSINI, 2011, p. 96).

A valorização dos atores sociais locais e o respeito ao saber local não é incompatível com o processo de integração regional e de internacionalização da educação superior e da produção acadêmica. Isso porque tais processos, que parecem ser eminentemente acadêmicos, tornam-se um conjunto de quatro ações combinadas: a) internacionalização; b) integração regional; c) desenvolvimento sustentável; d) respeito ao conhecimento local (AZEVEDO, 2009 , p. 185). Apresenta-se, a seguir, um diagrama com a finalidade de se imaginar como isso poderia ocorrer no campo acadêmico (fundamentalmente universitário); algo como um procedimento de feedback (campo acadêmico $\mathrm{x}$ sociedade) em que o saber local, a integração regional, a internacionalização 
e o desenvolvimento (sustentável) estivessem organicamente assentados (AZEVEDO, 2009, p. 187).

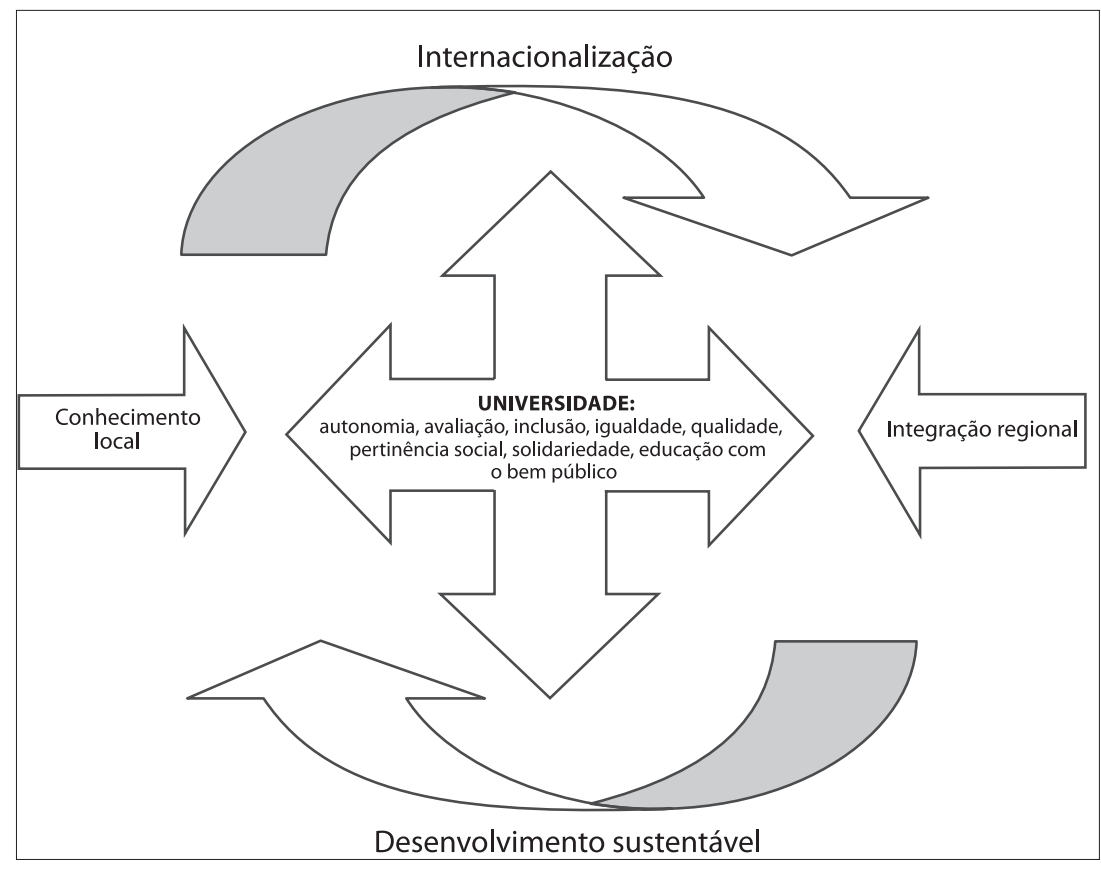

Figura 1: Modelo de retroalimentação (universidade, integração regional, conhecimento local e desenvolvimento sustentável)

Fonte: Azevedo, 2009, p. 187.

Morosini chama a atenção para a passagem da cooperação internacional inicial, baseada na formação de recursos humanos, e, em seguida, da cooperação internacional avançada, com base na produção conjunta de conhecimento, caracterizando esta última como a forma mais elaborada de cooperação (MOROSINI, 2011, p. 104). No entanto, não é ocioso lembrar que o conhecimento, mesmo sendo produzido em cooperação internacional, está impregnado dos contextos dos polos conveniados; ou seja, o texto (conhecimento produzido), ao circular, carrega consigo contextos e marcas históricas dos campos de criação intelectual (nacionais e global). Conforme ressalta Bourdieu, "os intercâmbios internacionais estão sujeitos a uma série de fatores estruturais que geram mal-entendidos. O primeiro fator: o fato de que os textos circulam sem seu contexto" (BOURDIEU, 2002, p. 4).? Esse equívoco é ainda mais delicado quando se sabe que 
a vida intelectual é o lugar, como todos os outros espaços sociais, de nacionalismos e imperialismos; e os intelectuais transmitem, quase tanto quanto os outros, preconceitos, estereótipos, ideias, representações muito sumárias, elementares, que se alimentam de acidentes da vida cotidiana, de incompreensões, mal-entendidos, de deformações [...]. Tudo isso me faz pensar que o estabelecimento de um genuíno internacionalismo científico, que, em minha opinião, é o começo do internacionalismo tal como deve ser, não pode se formar sozinho. (BOURDIEU, 2002, p. 3-4) ${ }^{8}$

No Brasil, o financiamento de projetos de pesquisa em cooperação internacional pelas agências públicas de apoio (Capes, CNPq, fundações estaduais etc.) é resultado de seleção, a partir de edital, por intermédio dos pareceres e comitês de pares que classificam e fazem homologias, tendo por referência o espaço estruturado de posições sociais do campo acadêmico. Morosini observa que

os acordos bilaterais são programas que fomentam projetos conjuntos de pesquisa entre grupos brasileiros e estrangeiros. São financiadas missões de trabalho (intercâmbio de professores), bolsas de estudo (intercâmbio de alunos), além de uma quantia para o custeio das atividades do projeto. É imprescindível que os grupos de pesquisa brasileiros integrem programas de pós-graduação reconhecidos pelo MEC, preferencialmente com conceitos 5,6 ou 7, na avaliação da Capes. (MOROSINI, 2011, p. 104)

Analogamente, Bourdieu (2002, p. 5), referindo-se à circulação internacional de ideias, nota a identidade, homologias e as alianças que se firmam entre os atores sociais conveniados, para se alcançarem as traduções e as publicações internacionais Assim, ele afirma:

O que eu chamo de "interesse" pode ser o efeito de afinidades relacionadas com a identidade (ou homologia) de posições em campos diferentes [...]. Podem-se compreender esses intercâmbios como alianças na lógica das relações de poder, como, por exemplo, maneiras de reforçar uma posição dominada, ameaçada. (BOURDIEU, 2002, p. 5) ${ }^{9}$

\section{O ESTADO E O CAMPO DAS CIÊNCIAS (SEM FRONTEIRAS)}

A atividade intelectual somente avança quando há cooperação, e não apenas para que um investigador forneça o que falta ao outro, mas para que o êxito de sua atividade entusiasme o próximo. Muitas vezes o Estado cria obstáculos à atividade científica, ainda que esse não tenha sido seu propósito. Em consequência, para evitar novos danos, o Estado deve sempre respeitar a lógica interna científica. (HUMDOLDT, 1997, p. 83) 
O Estado, meta-ator social por excelência, ${ }^{10}$ cumpre um especial papel de "criador" "emulador" por intermédio de políticas públicas e de ações de suas agências de financiamento (Capes, CNPq, Finep etc.), como patrocinador e catalisador do desenvolvimento da pesquisa, da inovação tecnológica, pósgraduação e da internacionalização da educação superior. O então Ministro da Ciência, Tecnologia e Inovação, Aloizio Mercadante, no início da gestão da presidência Dilma Rousseff (2010-2014), demonstrando sua convicção do papel do Estado brasileiro com relação ao objetivo de se alcançar a chamada "sociedade do conhecimento", na apresentação da "Estratégia Nacional de Ciência, Tecnologia e Inovação 2012 - 2015", afirma:

No meu discurso de posse no MCTI, em janeiro de 2011, assinalei o que é o principal desafio que o Brasil terá de enfrentar se quiser se transformar em um país efetivamente desenvolvido, com uma economia eficiente e competitiva: preparar-se para a "sociedade do conhecimento"." Essa é a diretriz estratégica para as próximas décadas que, no nosso caso, implica combinar educação universal de qualidade, pesquisa científica, inovação e inclusão social". (BRASIL, 2012a)

O sucessor de Aloizio Mercadante no Ministério da Ciência, Tecnologia e Inovação, Marco Antônio Raupp, ex-presidente da SBPC, assumiu o MCTI em 24 de janeiro de 2012. Em entrevista ao Jornal da USP, mantém o compromisso de Estado (do MCTI) com a internacionalização da ciência e a crença na chamada "sociedade do conhecimento". Raupp afirma, por exemplo, que o Programa Ciência sem Fronteiras ${ }^{12}$ atende a dois aspectos principais. O primeiro "é o esforço de internacionalização maior da ciência brasileira" (RAUPP, 2012, p. 5). O segundo aspecto que norteia o programa vem a ser o

reconhecimento de que certas áreas [que] precisam de maior estímulo, porque contribuem diretamente na modernização da sociedade, no desenvolvimento econômico do país. São as ciências naturais, ciências das engenharias, computação, entre outras. Estamos focando essas áreas, porque, em termos de pós-graduação, no Brasil, as ciências da engenharia caíram. Elas não ocupam o lugar que deveriam ocupar. Esperamos que esse instrumento seja utilizado para que elas se fortaleçam. É o reconhecimento de que essas áreas são importantes para o desenvolvimento, dentro do que se chama sociedade do conhecimento. (RAUPP, 2012, p. 5)

O discurso a esse favor já vinha sendo desempenhado pelo governo de Luís Inácio Lula da Silva (2003-2006 e 2007-2010), por intermédio do Plano de Aceleração do Crescimento (PAC), conforme havia percebido Morosini, nas considerações finais de seu artigo: 
a Política Nacional de Ciência, Tecnologia e Inovação está sendo direcionada, via Plano de Aceleração do Crescimento - PAC da Ciência - para a expansão e a consolidação de um sistema nacional de C,T\&l; a promoção da inovação tecnológica nas empresas; a pesquisa, o desenvolvimento e a inovação em áreas estratégicas (editais específicos), como biotecnologia, nanotecnologia, tecnologia da informação e comunicação, agronegócios, insumos para a saúde e energia nuclear, objetivando acompanhar o concerto internacional. Também é identificada a busca de desenvolvimento social. Paralelamente a tais políticas, há um desaquecimento da demanda por balcão, ou seja, ao fomento de temáticas de livre escolha do pesquisador, como ofertas para áreas não prioritárias. (MOROSINI, 2011, p. 107)

O Estado, no Brasil, comprovando seu papel de meta-ator social, inclusive no campo acadêmico, estabelece a regulação da C,T\&I pelos mecanismos e agências anunciados anteriormente, e direciona o financiamento prioritário para áreas consideradas estratégicas. Os editais publicados pelas agências e órgãos estatais conferem os princípios de legitimidade, legalidade, publicidade, impessoalidade e eficiência requeridos pela administração pública. A Figura 2, extraída da "Estratégia Nacional de Ciência, Tecnologia e Inovação 2012 - 2015", ilustra a complexidade de atores sociais envolvidos no campo acadêmico e da produção de C,T\&I no Brasil.

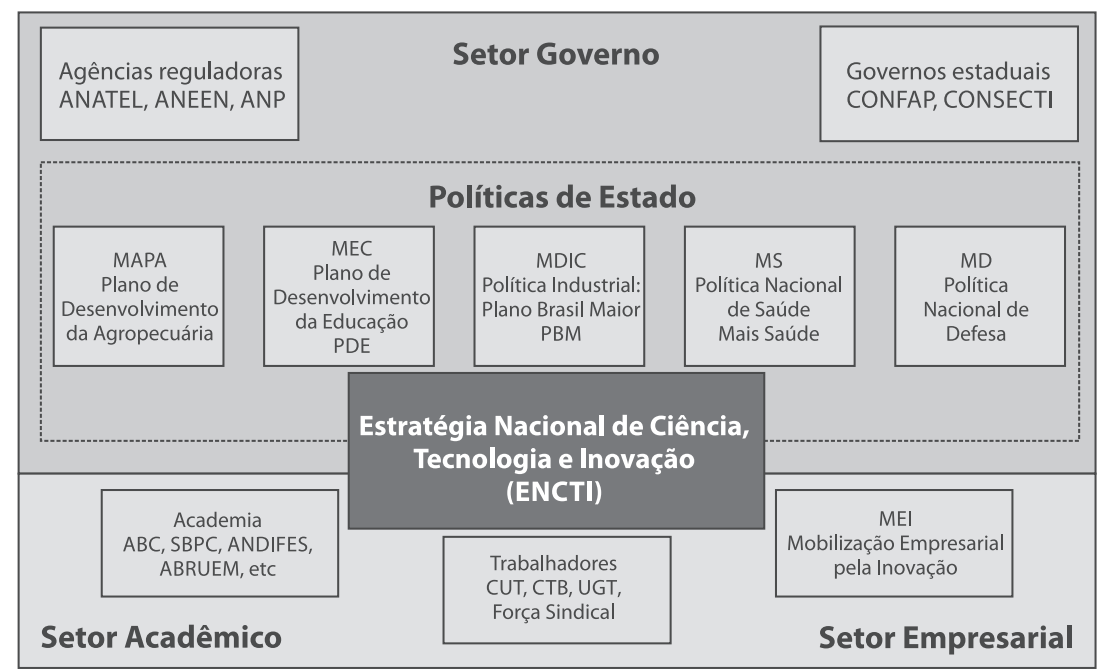

Figura 2 - Articulação da política de C,T\&l com as principais políticas de Estado e a integração dos atores sociais.

Fonte: Brasil, 2012a, p. 27. 
Dessa forma, a política de incentivo a áreas consideradas estratégicas, por meio de editais, centraliza a política científica, publiciza a concorrência por recursos e, ao estabelecer a regulação da produção científica, diminui a autonomia do campo acadêmico, desalentando, por exemplo, os pesquisadores e os colegiados de pós-graduação para o trabalho em áreas não anunciadas como prioritárias nos editais. O Programa Ciência sem Fronteiras comprova esse sentido regulatório-restritivo do campo acadêmico pelo Estado. A "Estratégia Nacional de Ciência, Tecnologia e Inovação 2012 - 2015", apresentada pelo Ministro Aloizio Mercadante do MCTI, não deixa margem a dúvidas:

o Programa Ciência sem Fronteiras (CsF) tem o objetivo geral de promover de maneira acelerada o desenvolvimento tecnológico e estimular os processos de inovação no Brasil por meio da qualificação de estudantes e pesquisadores brasileiros, especialmente nos níveis de pós-graduação, em áreas consideradas prioritárias e estratégicas para o desenvolvimento do país. (BRASIL, 2012a, p. 18)

O Programa Ciência sem Fronteiras tem formato compatível com o padrão de editais das agências e órgãos estatais no Brasil. Observa-se também, nesse programa de internacionalização da educação superior, esse comportamento de "metarregulação":

a crescente interlocução entre Governo Federal, Estados e Municípios, agências de fomento, institutos de pesquisa, universidades e empresas elevou a consolidação institucional do sistema de C,T\&l a um novo patamar. Hoje a C,T\&I no Brasil apresenta um sistema de governança sistêmico que conta com ferramentas mais eficazes de acompanhamento e avaliação dos resultados e maior integração entre as políticas, instrumentos e agências. (BRASIL, 2012a, p. 11)

O que Mercadante chama de "interlocução" entre Estado, agências públicas, instituições científicas e empresas poderia também ser interpretado como heteronomia do campo acadêmico, pois se trata, como ressalta Bourdieu, de uma relação de independência na dependência ou de dependência na independência, em função de financiamentos regulados pelo Estado por regras explícitas e implícitas (BOURDIEU, 2004, p. 55). Para o melhor sucesso das atividades científicas, Wilhelm von Humboldt adverte para o fato de que "o Estado não pode tratar suas universidades como se fossem escolas de primeiro e segundo grau ou de ensino profissionalizante. Tampouco pode servir-se de sua academia como se fosse uma assembleia de especialistas" (HUMBOLDT, 1997, p. 88). 
Assim, esse especial fenômeno de "interlocução" (heteronomia), mencionado por Mercadante, entre o Estado (ministérios, agências, fundações etc.), empresas e instituições acadêmicas torna-se ainda mais evidente no âmbito da pós-graduação no Brasil, pois é o locus especial de produção científica e da internacionalização da educação superior. De acordo com Morosini,

o desenvolvimento histórico e as políticas nacionais de C\&T vêm acarretando, na realidade brasileira em termos de IES, o predomínio do modelo periférico de internacionalização da educação superior, ou seja, a internacionalização está focada na pós-graduação, e não na universidade como um todo. E mesmo quando consideramos a pós-graduação, não há distribuição igual do grau de internacionalização entre programas, tampouco dentro de um mesmo programa de pós-graduação. (MOROSINI, 2011, p. 107)

O modelo de internacionalização da ciência e da educação superior, periférico, desigual e subordinado, é condizente com o modelo de desenvolvimento com similares características, dominado pelos interesses do capital financeiro e do agronegócio preponderantes no Brasil. Dessa forma, a estratégia de Estado e as políticas públicas para a educação superior e para o complexo de C,T\&l, mais recentemente, têm se marcado pelas regulações e sinalizações, para que os atores sociais do campo acadêmico brasileiro convertam os esforços para determinadas áreas das ciências naturais e para a formação em tecnologia. Nesse sentido, foi publicado o Decreto 7.642, de 13 de dezembro de 2011, instituindo o Programa Ciência sem Fronteiras com objetivos, em seu art. $2^{\circ}$, tais como:

I - promover, por meio da concessão de bolsas de estudos, a formação de estudantes brasileiros, conferindo-Ihes a oportunidade de novas experiências educacionais e profissionais voltadas para a qualidade, o empreendedorismo, a competitividade e a inovação em áreas prioritárias e estratégicas para o Brasil;

II - ampliar a participação e a mobilidade internacional de estudantes de cursos técnicos, graduação e pós-graduação, docentes, pesquisadores, especialistas, técnicos, tecnólogos e engenheiros, pessoal técnico-científico de empresas e centros de pesquisa e de inovação tecnológica brasileiros, para o desenvolvimento de projetos de pesquisa, estudos, treinamentos e capacitação em instituições de excelência no exterior [...];

V - promover a cooperação internacional na área de ciência, tecnologia e inovação [...];

VIII - contribuir para o aumento da competitividade das empresas brasileiras; e 
IX - estimular e aperfeiçoar as pesquisas aplicadas no país, visando ao desenvolvimento científico e tecnológico e à inovação. (BRASIL, 13 dez. 2011, sem grifos no original).

De maneira resumida, as metas a serem alcançadas até 2015 pelo Programa Ciência sem Fronteiras, por modalidade, são: ${ }^{13}$

\begin{tabular}{|l|c|}
\hline MODALIDADE & N $^{\circ}$ DE BOLSAS \\
\hline Doutorado sanduíche & 24.600 \\
\hline Doutorado pleno & 9.790 \\
\hline Pós-doutorado & 11.560 \\
\hline Graduação sanduíche & 27.100 \\
\hline Treinamento de especialista no exterior (empresa) & 700 \\
\hline Jovem cientista de grande talento (no Brasil) & 860 \\
\hline Pesquisador visitante especial (no Brasil) & 390 \\
\hline TOTAL & 75.000 \\
\hline
\end{tabular}

Fonte: BRASIL, 15 out. 2012b, extraído de http://www.cienciasemfronteiras.gov.br

As áreas prioritárias do Programa Ciência sem Fronteiras estão relacionadas às Ciências Naturais, demonstrando à filiação dos formuladores dessa política pública que são esses os ramos das ciências que produzem valor e que podem encaminhar o País para o desenvolvimento de uma economia baseada no conhecimento. As áreas prioritárias para a internacionalização financiada com recursos públicos do Programa Ciência sem Fronteiras são: Engenharias e demais áreas tecnológicas; Ciências Exatas e da Terra; Biologia, Ciências Biomédicas e da Saúde; Computação e Tecnologias da Informação; Tecnologia Aeroespacial; Fármacos; Produção Agrícola Sustentável; Petróleo, Gás e Carvão Mineral; Energias Renováveis; Tecnologia Mineral; Biotecnologia; Nanotecnologia e Novos Materiais; Tecnologias de Prevenção e Mitigação de Desastres Naturais; Biodiversidade e Bioprospecção; Ciências do Mar; Indústria Criativa (voltada a produtos e processos para desenvolvimento tecnológico e inovação); Novas Tecnologias de Engenharia Construtiva; Formação de Tecnólogos (BRASIL, 15 out. 2012).

De maneira similar, o Instituto de Estudos para o Desenvolvimento Industrial (IEDI), um dos poucos think tank ligados à promoção da indústria nacional, havia publicado, em novembro de 2011, o texto “Uma comparação entre a agenda de inovação da China e do Brasil", constatando que

cerca de $60 \%$ dos profissionais formados na China são tecnólogos ( 3 anos) e $40 \%$ têm formação plena. No Brasil esses números se invertem: 70\% têm formação plena e $30 \%$ são tecnólogos. No começo da década, a disponibilidade de profissionais relativa à população era o dobro na China. Passados 
apenas oito anos, as diferenças se ampliaram enormemente: em 2009, já era cinco vezes maior que o número per capita do Brasil. Evidente que, em termos absolutos, essas diferenças são gritantes: os quase 2 milhões de profissionais formados são cerca de 35 vezes o número de egressos do Brasil [...]. Apesar desse forte crescimento na formação de recursos humanos, em 2010, o Conselho de Estado do governo chinês lançou, para fazer frente aos seus novos desafios, um novo plano para a formação de recursos humanos qualificados. Entre os objetivos está elevar o número de pesquisadores a 3,8 milhões em 2020, com 40 mil cientistas de altíssima qualificação nas áreas-chave de inovação. Em termos per capita, a meta é elevar o número de pesquisadores para 43 por mil habitantes até 2020 (ante 25 por mil em 2008), bem como aumentar a escolaridade bruta superior de $24 \%$ para $40 \%$ em dez anos. (IEDI, 2011, p. 12)

O Quadro 1 ilustra, de maneira absoluta e relativa, as realidades chinesa e brasileira de concluintes da educação superior e da pós-graduação, justificando, de certa maneira, a necessidade de implementação, no Brasil, de políticas públicas de expansão da educação superior e de incremento de financiamento para a Ciência, Tecnologia e Inovação (C,T\&l).

Quadro 1 - Concluintes de ensino superior e da pós-graduação por área de estudo: Brasil e China - 2009, em número absoluto e per capita.

\begin{tabular}{|c|r|r|r|r|r|r|}
\hline & Brasil & $\begin{array}{c}\text { Brasil } \\
(\%)\end{array}$ & $\begin{array}{c}\text { Brasil } \\
\mathbf{( p / 1 0} \\
\text { mil hab.) }\end{array}$ & \multicolumn{1}{|c|}{ China } & $\begin{array}{c}\text { China } \\
(\%)\end{array}$ & $\begin{array}{c}\text { China } \\
(\mathbf{p} / \mathbf{1 0} \\
\text { mil hab. }\end{array}$ \\
\hline Ensino Superior (Integral) & 722.202 & $100,0 \%$ & 37,5 & 2.455 .359 & $100,0 \%$ & 18,4 \\
\hline Ciências & 64.291 & $8,9 \%$ & 3,3 & 264.494 & $10,8 \%$ & 2,0 \\
\hline Engenharia & 38.826 & $5,4 \%$ & 2,0 & 763.635 & $31,1 \%$ & 5,7 \\
\hline Ensino Superior (3 anos) & 104.726 & $100,0 \%$ & 5,4 & 2.855 .664 & $100,0 \%$ & 21,4 \\
\hline Ciências & - & $0,0 \%$ & 0,0 & 1.543 & $0,1 \%$ & 0,0 \\
\hline Engenharia & 16.601 & $15,9 \%$ & 0,9 & $1.154,793$ & $40,4 \%$ & 8,6 \\
\hline Ensino Superior (Total) & 826.928 & $100,0 \%$ & 43,0 & 5.311 .023 & $100,0 \%$ & 39,7 \\
\hline Ciências & 64.291 & $7,8 \%$ & 3,3 & 266.037 & $5,0 \%$ & 2,0 \\
\hline Engenharia & 55.427 & $6,7 \%$ & 2,9 & 1.918 .428 & $36,1 \%$ & 14,4 \\
\hline Doutores & 11.368 & $100,0 \%$ & 0,5 & 48.658 & $100,0 \%$ & 0,4 \\
\hline Ciências & 2.388 & $21,0 \%$ & 0,1 & 9.570 & $19,7 \%$ & 0,1 \\
\hline Engenharia & 1.284 & $11,3 \%$ & 0,1 & 17.386 & $35,7 \%$ & 0,1 \\
\hline Mestres & 38.800 & $100,0 \%$ & 1,9 & 322.615 & $100,0 \%$ & 2,4 \\
\hline Ciências & 5.819 & $15,0 \%$ & 0,3 & 32.252 & $10,0 \%$ & 0,2 \\
\hline Engenharia & 4.986 & $12,9 \%$ & 0,3 & 113.128 & $35,1 \%$ & 0,8 \\
\hline
\end{tabular}

Fonte: China Statistical Yearbook, 2010; INEP, Censo Escolar de 2008 e MCT (IEDI, 2011, p. 11). 
Enfim, a maior intensidade de regulação do Estado - considerado como um meta-ator social por excelência do campo acadêmico - tem se fundamentado, conforme mencionado anteriormente, na busca por uma economia baseada no conhecimento (na chamada sociedade do conhecimento) com vista à fabricação de produtos tecnologicamente sofisticados e com maior valor agregado. Essa, pelo que se nota, tem sido a lógica dos argumentos em favor da relativa limitação da oferta de financiamento em editais universais e da profusão de editais e de políticas de indução para o avanço de determinadas áreas das ciências naturais. Isso tem gerado, por consequência, perda de autonomia (independência) do campo acadêmico, maior dependência de políticas, editais e incentivos dirigidos pelo Estado (ministérios, secretarias etc.), fundos setoriais e agências de apoio (Capes, CNPq, Finep), fundações estaduais etc. e, ainda, delimitação da circulação internacional de ideias com a devida alocação de recursos públicos às áreas consideradas estratégicas.

\section{CONSIDERAÇÕES FINAIS}

O MCTI tem o papel de impulsionar a nova economia brasileira, apoiando os setores portadores de futuro, preparando o Brasil para a economia do conhecimento e da informação, auxiliando na transição para uma economia verde e criativa e contribuindo para a inclusão produtiva e social. Nesse sentido, a ENCTI (Estratégia Nacional de Ciência, Tecnologia e Inovação 2012-2015) estabelece diretrizes para consolidar um Sistema Nacional de C,T\&l capaz de conjugar esforços em todos os âmbitos - federal, estadual, municipal, público e privado - e promover o aperfeiçoamento do marco legal e a integração dos diferentes instrumentos de apoio a C,T\&l existentes no País. (BRASIL, 2012a, p. 96)

A internacionalização da educação superior e a circulação de ideias para além das fronteiras nacionais são calcadas, esquematicamente, em dois princípios contraditórios: a solidariedade internacional e a concorrência em um mercado global de educação e conhecimento. Essas duas expressões são como oximoros, isso é, um termo silencia o outro. Em geral, quando essas expressões aparecem ao mesmo tempo em uma política de internacionalização é devido à força de retórica.

Assim, a opção pela solidariedade internacional no mundo das ciências prescinde dos acordos mercadorizantes da educação e do conhecimento ao estilo GATS da OMC: ${ }_{i}^{14}$ dispensa, também, a assinatura de contratos de importação de ideias e de convênios utilitaristas no campo da 
educação superior. A solidariedade internacional implica, mesmo que esse não seja o objetivo principal, na conquista de soft power (poder brando), pois esse é o poder de atração de uma nação sobre outra(s), sem a necessidade de imposição, coerção ou pagamentos, o que seria o uso do hard power (poder duro). Soft power, conforme Nye Jr. (2004, p.x), é proveniente da atratividade da cultura, ideias e políticas de um país; para isso, mesmo com o sentido da solidariedade, a produção de ideias e a educação superior cumprem papel fundamental na geração de soft power. ${ }^{15}$

Já a concorrência comercial é o motor do funcionamento de mercados educacionais e faz parte das regras do jogo nas arenas de disputa por hard power, que é o poder que emana da força, coerção e pagamento. Nesse caso, os países centrais fazem de suas instituições de educação superior espaços de atratividade de estudantes estrangeiros, tratando-as pragmaticamente como empresas de venda de serviços e como instrumentos utilitaristas de conquista de poder global.

Entretanto, se solidariedade internacional e concorrência de mercado são expressões de uma díade contraditória, soft power e hard power, em certas ocasiões, complementam-se. A combinação de ambos - o soft power, o poder da persuasão e atração, e o hard power, o poder obtido por coerção, força e pagamento - é denominada por Nye Jr. (2011, p. 20-24) de smart power (poder inteligente). Dessa maneira, pode-se inferir que a oferta de serviços educacionais pelas universidades dos países centrais é um exemplo de smart power, pois, ao mesmo tempo, tal relação submete-se às duras regras do comércio transnacional de serviços, frequentemente intermediado por brokers, e configura-se em atratividade política e transmissão cultural.

Nesse sentido, políticas de mobilidade estudantil de países periféricos (potenciais compradores de educação superior), quando não bem reguladas e organizadas - como preparo prévio dos viajantes para a vida intercultural e garantia de condições adequadas de estudo, pesquisa e trabalho no retorno para o campo acadêmico nacional -, podem significar, contrariamente, apenas uma relação mercantil; em outras palavras, uma importação de serviços educacionais - na linguagem da OMC, comsuption abroad (consumo no estrangeiro) - e o exercício de atratividade política e da influência cultural em favor dos países centrais.

Aliás, esse é o grande risco que corre o Programa Ciência sem Fronteiras, já que foi concebido "interesseiramente" para o treinamento nas áreas de tecnologias com vista ao aumento da produtividade da economia e à promoção da "sociedade do conhecimento" ou da "economia baseada no conhecimento". ${ }^{16}$ Parafraseando Hans de Wit, isso pode ser um mito, pois a 
internacionalização é um processo intercultural de promoção com qualidade da educação superior e da pesquisa (WIT, 2011, p. 6). Se a internacionalização da educação superior for considerada instrumentalmente como um catalisador das atividades econômicas, perde-se de vista a solidariedade e corre-se o risco de se tornar somente uma correia de transmissão da hegemonia dos países centrais, de inculcação dos valores e da aceitação de determinado arbitrário cultural - com a conta paga pelos países periféricos -, reforçando-se o poder de dominação dos dominantes.

HIGHER EDUCATION, INTERNATIONALIZATION AND CIRCULATION OF IDEAS: ADJUSTING TERMS AND EXPLODING MYTHS

ABSTRACT: This article sets out to analyze the phenomenon of the internationalization of higher education, sharing of culture and international circulation of ideas. The text, based on Pierre Bourdieu's "Theory of social fields", analyzes the current manifestation of the internationalization of higher education, which could acquire meanings of solidarity or commodification. The article also deals with the "Science without Borders" Program and Brazil's "National Strategy for Science, Technology and Innovation 2012-2015".

KEYWORDS: Internationalization. Higher education. Science without Borders.

EDUCACIÓN SUPERIOR, INTERNACIONALIZACIÓN Y CIRCULACIÓN DE IDEAS: AJUSTANDO LOS TÉRMINOS Y DESHACIENDO MITOS

RESUMEN: El artículo tiene por objetne por objetivo analizar el fenómeno de la internacionalización de la educación superior, la difusión cultural y la circulación internacional de las ideas. De esa forma, el texto fue desarrollado usando como referencia la "teoría de los campos sociales" de Pierre Bourdieu para investigar la actual manifestación de la internacionalización de la educación superior, que puede adquirir los sentidos de la solidaridad o de la mercantilización. El artículo también trata sobre el Programa "Ciencias sin Fronteras" y la "Estrategia Nacional de Ciencia, Tecnología e Inovación 2012 - 2015" del Brasil.

Palabras Claves: Internacionalización. Educación Superior. Ciencia sin Fronteras.

\section{NOTAS}

1. "Je souhaite aujourd'hui vous proposer quelques réflexions qui voudraient échapper au rituel de la célébration de l'amitié franco-allemande et des considérations obligées sur l'identité et l'altérité. Je pense qu'en matière d'amitié, comme en toute matière, la lucidité n'est pas du tout antinomique avec l'affection, bien au contraire. Je voudrais donc essayer de proposer quelques réflexions sur les conditions sociales de 
la circulation internationale des idées; ou, pour employer un vocabulaire économique qui produit toujours un effet de rupture, sur ce qu'on pourrait appeler l'import-export intellectuel" (BOURDIEU, 2002, p. 1).

2. “On croit souvent que la vie intellectuelle est spontanément internationale. Rien n'est plus faux" (BOURDIEU, 2002, p. 3).

3. Analisando o processo de integração e regionalização da educação superior no Mercosul e na Europa, nota Azevedo: "ao aceitarem o convite para a integração regional, tacitamente, as Instituições de Educação Superior contraem mais obrigações do que apenas o compromisso de compatibilização e de comparabilidade de seus sistemas de educação superior, pois o esforço de formação de um espaço regional de educação superior pressupõe a internacionalização acadêmica que, por sua vez, não se trata de um simples mecanismo de permeabilização de fronteiras, mas, sim, um complexo processo de integração a um campo social de produção científica mundializado em que os diversos atores sociais travam relações com vista a intercambiar, a cooperar e a compartilhar solidariamente (ou, ao contrário, a competir) em suas áreas de atuação e em seus espaços de influência" (AZEVEDO, 2009, p. 186).

4. O campo científico no Brasil é fortemente regulado pela regras e normas referentes à pós-graduação, operadas diretamente pelos próprios pares acadêmicos ou mediadas pela Capes.

5. BROVETTO, J. International cooperation in higher education. In: Higher education in the XXI century: view of Latin America and the Caribbean, Unesco, p. 1119-1134, 1998.

6. DIDRIKSSON, A. Reformulación de la cooperación internacional en la educación superior de América Latina y el Caribe, 2005.

7. “[...] les échanges internationaux sont soumis à un certain nombre de facteurs structuraux qui sont générateurs de malentendus. Premier facteur: le fait que les textes circulent sans leur contexte" (BOURDIEU, 2002, p. 4).

8. "La vie intellectuelle est le lieu, comme tous les autres espaces sociaux, de nationalismes et d'impérialismes, et les intellectuels véhiculent, presque autant que les autres, des préjugés, des stéréotypes, des idées reçues, des représentations très sommaires, très élémentaires, très élémentaires, qui se nourrissent des accidents de la vie quotidienne, des incompréhensions, des malentendus, des blessures [...]. Tout cela me fait penser que l'instauration d'un véritable internationalisme scientifique, qui, à mes yeux, est le début d'un internationalisme tout court, ne peut pas se faire toute seule" (BOURDIEU, 2002, p. 3-4).

9. “Ce que j'appelle 'intérêt', ce peut être l'effet des affinités liées à l'identité (ou I'homologie) des positions dans des champs différents [...].On peut comprendre ces échanges comme des alliances, donc dans la logique des rapports de force, comme, par exemple, des manières de donner de la force à une position dominée, menacée (BOURDIEU, 2002, p. 5). 
10. Uma análise do papel do Estado como um meta-ator de políticas públicas pode ser encontrada em trabalho apresentado, em 2006, na 29a reunião nacional da Anped e publicado em coletânea organizada pelo GT-11 (Educação Superior) da Anped como capítulo de livro (AZEVEDO, 2006 - referências completas ao final).

11. Para maior discussão sobre "a economia baseada no conhecimento" e a chamada "sociedade do conhecimento", pode-se consultar o texto apresentado por um dos autores na reunião da Anped de 2012 - "A economia baseada no 'cercamento' do conhecimento: globalização, seigniorage e mercadorias fictícias" (AZEVEDO, 2012).

12. O Programa será discutido com mais pormenores adiante.

13. De acordo com o site de divulgação do Programa Ciência sem Fronteiras, serão alocados mais e R\$ 3.2 bilhões para a execução do Programa até 2015 e "além das 75.000 bolsas oferecidas pelo Governo Federal, mais 26.000 bolsas serão concedidas com recursos da iniciativa privada. Portanto, o Programa Ciência sem Fronteiras irá oferecer 101.000 bolsas a estudantes e pesquisadores no país e no exterior" (BRASIL, 15 out. 2012b, extraído de http://www.cienciasemfronteiras.gov.br).

14. GATS (General Agreement on Trade in Services) é a sigla em inglês para Acordo Geral sobre Comércio de Serviços (AGCS). Trata-se de um acordo da Organização Mundial do Comércio (OMC) que entrou em vigor em janeiro de 1995. Pode-se encontrar uma análise mais detalhada em Azevedo, 2011 (verificar referências).

15. Pode-se identificar semelhanças nos conceitos de soft power e hard power, elaborados por Joseph Nye Jr., com o conceito de Estado, de Antonio Gramsci. Para o pensador italiano, o Estado "não se impõe somente pela força, mas também pela ideologia e pela cultura, fenômenos sociais que, em grande medida, têm a escola e a educação como vetores [...]. Desse modo, ao Estado-coerção é adicionado o Estado-consenso, isso é, em Gramsci o Estado se dilata. A sua'Teoria Ampliada de Estado' compreende o Estado como sendo a soma da força e o consenso" (NOSELLA; AZEVEDO, 2009, p. 85).

16. Raupp, ao responder à questão afirma que "o Ciência sem Fronteiras tem um orçamento destinado pelo MCTI de R\$ 3,2 bilhões, mas também tem a participação de empresas parceiras. Como vão funcionar essas parcerias?". Elucida que "a ideia é alocar pesquisadores nas empresas, pessoas com melhor treinamento científico, com uma visão internacional maior, para que ajudem no processo de inovação. É uma política concatenada que procura estimular e se relacionar com as necessidades das empresas. São dois tipos de parcerias. No primeiro, estão as empresas que querem financiar a formação de seus funcionários em parceria com o governo. É a categoria de especialistas, técnicos que vão para o exterior se capacitar em uma determinada tecnologia. Também há profissionais interessados em cursar mestrado ou doutorado. O outro tipo é a parceria feita com associações empresariais, como a Febraban (Federação Brasileira de Bancos) e a CNI (Confederação Nacional da Indústria), que estão dando bolsas como se fossem agências de fomento, porque compartilham da opinião de que temos de levar o ambiente de pesquisa e de desenvolvimento para dentro do 
sistema produtivo. Sem inovação não há salvação para o processo de crescimento econômico das empresas dentro do País" (RAUPP, 2012).

\section{REFERÊNCIAS}

AZEVEDO, M. L. N. de. A integração dos sistemas de educação superior na Europa: de Roma a Bolonha ou da integração econômica à integração acadêmica. In: SILVA JR., J. R.; OLIVEIRA, J. R.; MANCEBO, D. Reforma universitária: dimensões e perspectivas. Campinas: Alínea/Anped, 2006.

AZEVEDO, M. L. N. de. Integração regional e educação superior: regulações e crises no Mercosul. In: FERREIRA, E. B.; OLIVERIA, D. A. Crise da Escola e políticas educativas. Belo Horizonte: Autêntica, 2009.

AZEVEDO, M. L. N. de. O campo global da educação superior, as organizações internacionais e a hegemonia mercadorizante. In: OLIVEIRA, D. A.; PINI, M. E.; FELDFEBER, M. Políticas educacionais e trabalho docente. Belo Horizonte: Fino Traço, 2011.

AZEVEDO, M. L. N. de. A economia baseada no "cercamento" do conhecimento: globalização, seigniorage e mercadorias fictícias. Anais da 35a Reunião Anual da ANPEd. Porto de Galinhas/PE: 2012. Disponível em: http://35reuniao.anped.org.br/trabalhos. Acesso em: 02 out. 2012.

BOURDIEU, P. Les conditions sociales de la circulation internationale des idées. In: Actes de la recherche en sciences sociales. v. 145, décembre 2002. La circulation internationale des idées. p. 3-8, doi: 10.3406/arss.2002.2793.

BRASIL. Decreto 7.642/2011, de 13 de dezembro de 2011. Disponível em: http://www. planalto.gov.br/ccivil_03/_Ato2011-014/2011/Decreto/D7642.htm. Acesso em: 02 out. 2012.

BRASIL. Estratégia Nacional de Ciência, Tecnologia e Inovação 2012 - 2015. Balanço das Atividades Estruturantes. Ministério da Ciência, Tecnologia e Inovação (MCTI). Brasília: MCTI, 2012a.

BRASIL. Ciência sem Fronteiras. Ministério da Ciência, Tecnologia e Inovação (MCTI). Disponível em: http://www.cienciasemfronteiras.gov.br/web/csf/home. Acesso em: 15 out. 2012 b.

EAGLETON, T. The idea of culture. Oxford: Blackwell Publishers, 2000.

HUMDOLDT, W. V. Sobre a organização interna e externa das Instituições Científicas Superiores em Berlim. In: CASPER, G; HUMBOLDT, W. V. Um mundo sem universidades? Rio de Janeiro: EDUERJ, 1997.

IEDI. Uma comparação entre a agenda de inovação da China e do Brasil. Trabalho preparado por Carlos Américo Pacheco (Unicamp) para o Instituto de Estudos para o Desenvolvimento Industrial (IEDI). São Paulo: IEDI, nov. 2011. 
MOROSINI, M. C. Internacionalização na produção do conhecimento em IES brasileiras: cooperação internacional tradicional e cooperação internacional horizontal. In: Educação em Revista, Revista do Programa de Pós-Gradução em Educação da Faculdade de Educação da UFMG, Belo Horizonte, v. 27, n. 01, p. 93-112, abr. 2011.

NOSELLA, P.; Azevedo, M. L. N. A educação em Gramsci. In: CALEGARI-FALCO, A. M. Sociologia da Educação: múltiplos olhares. Maringá: EDUEM, 2009.

NYE JR., J. Soft power: the means to success in world politics. New York: Public Affairs (Perseus Books): 2004.

NYE JR., J. The future of power. New York: Public Affairs (Perseus Books): 2011.

RAUPP, M. A. Entrevista do Ministro da Ciência, Tecnologia e Inovação (MCTI), Marco Antônio Raupp, a Márcia Furtado Avanza. Uma aposta na Internacionalização. Jornal da USP. São Paulo, Divisão de Mídias Impressas da Superintendência de Comunicação Social (SCS) da Universidade de São Paulo (USP), p. 5, 1-7 out. 2012.

WIT, H. de. Internationalization of Higher Education: nine misconceptions. International Higher Education. Center for International Higher Education. The Boston College. Boston, n. 64, Summer 2011, p. 6-7.

MÁRIO LUIZ NEVES DE AZEVEDO: professor na Universidade Estadual de Maringá (UEM), Curso de Graduação em Pedagogia e Programa de Pós-Graduação em Educação; pesquisador do CNPq.

E-mail: mario.de.azevedo@uol.com.br.

AFRÂNIO MENDES CATANI: professor na Faculdade de Educação da Universidade de São Paulo (USP), Curso de Graduação em Pedagogia e no Programa de Pós-Graduação em Educação; professor no Programa de Pós-Graduação em Integração da América Latina (PROLAM) - USP; pesquisador do CNPq.

E-mail: amcatani@usp.br 